\title{
Ceiling Patterns from the Tomb of Hepzefa
}

\author{
MARIA C. SHAW
}

PLATES $5-6$

Well-defined spiraliform patterns ${ }^{1}$ first appear in Egyptian art in the Middle Kingdom, mainly as scarab designs and, to a limited extent, as painted decoration on ceilings of certain XIIth Dynasty rock-cut tombs belonging to important nomarchs of provinces in Middle Egypt. ${ }^{2}$ Since such patterns are foreign to Egyptian decorative tradition, which rests primarily on rectilinear forms, ${ }^{3}$ and since on the contrary they are common in Crete, where they appear as early as the EM II period, they have attracted the attention of scholars particularly concerned with contacts in the Aegean in this early pe-

\footnotetext{
${ }^{1}$ For rudimentary forms of spiral designs which seem to be unrelated to the XIIth Dynasty versions, see $\mathrm{H}$. Kantor, The Aegean and the Orient in the Second Millenium B.C., Monograph I (Bloomington 1947) 22, 23 (hereafter Kantor).

2 Specifically, painted spiraliform patterns occur in the following tombs (listed chronologically): the tomb of Hepzefa at Assiut, W. S. Smith, Interconnections in the Ancient Near East: A Study of the Relationships between the Arts of Egypt, the Aegean, and Western Asia (New Haven and London 1965) fig. I67; the tomb of Ukhhotp, son of Ukhhotp and Mersi at Meir, where the spiral pattern is used in a painted border on a doorway, A. Blackman, The Rock Tombs of Meir, III (London 1915) pl. xxviri; the tomb of Wahka II at Qaw el Kebir, W. M. F. Petrie, Antaeopolis: the Tombs of Qaw (London I930) pl. I.

3 Typical examples of Egyptian surface designs are to be found on painted niches of Old Kingdom tombs at Saqqara, W. Emery, Great Tombs of the First Dynasty, III (Cairo I958) pls. 6-8, and J. Quibell, The Tomb of Hesy (Cairo 1913) pl. Ix; and later on the walls of statue recesses and on certain ceilings of Middle Kingdom tombs, Blackman (supra n. 2) and P. Newberry and E. Griffith, Beni Hasan, I (London I893) pl. vi. These consist of checkers, chevrons, zigzag lines, etc.

${ }^{4}$ Kantor, 21 n. 35, gives a bibliography of earlier studies. She concentrates on scarab designs and admits only a remote Minoan influence on painted Egyptian spiraliform patterns. She draws comparisons with the Minoan "quadruple spiral," which is rendered in a rectilinear fashion in the tomb of Wahka II at Qaw (Kantor 28) and with a motif that she describes as a "rectilinear version of two axially symmetrical S-spirals" in the tomb of Hepzefa (Kantor 29). F. Matz in his Die Frühkretischen Siegel (Berlin and Leipzig 1928) discusses a painted decorative border in the tomb of Ukhhotp at Meir (Blackman, supra n. 2), which he interprets as a system of intersecting S-spirals; he notes there a remote resemblance between the Meir border and certain cordiform Minoan ceramic patterns, though he emphasizes differences rather than similarities between them $(\mathrm{I} 77-\mathrm{I} 78)$.

${ }^{5}$ Kantor (supra n. I) 2 I-32.

${ }^{6} \mathrm{G}$. A. Reisner, $I E A$ 5 (I918) 79ff. Here Reisner describes the plan and the inscriptions of the tomb, but mentions only briefly the painted ceiling and the low-relief decoration of some of the walls. The designs on the ceiling are best described
}

riod. ${ }^{4}$ This research has been summarized and brought to completion in a study by Miss $\mathrm{H}$. Kantor. ${ }^{5}$

The XIIth Dynasty tomb of the nomarch Hepzefa at Assiut in Upper Egypt, which is only partially published, ${ }^{6}$ offers further evidence for the use of painted spirals in Egypt and may provide additional information on possible artistic connections with Crete. The tomb is of particular importance, for it is the earliest one known to have incorporated spiraliform motifs in its painted decoration (pl. 5, figs. I-4). ${ }^{7}$ Structurally this is the largest rock-cut

by the late W. S. Smith, first in The Art and Architecture of Ancient Egypt (London 1958) I $66 \mathrm{ff}$, and recently in Interconnections (supra n. 2) $135 \mathrm{ff}$, in which he includes a black-andwhite reproduction of a watercolor of part of the ceiling made by the Baroness von Bissing in I913. I visited the tomb in the spring of 1965 in connection with research for my doctoral thesis which discusses possible affinities between Minoan and Egyptian wall-painting of the Middle Kingdom. The photographs I took of the painted ceiling (infra, pl. 5, figs. I-2), though obscure because of the blackened condition of the surface, bring out certain features which do not entirely agree with reproductions hitherto published. Unfortunately, I cannot include colors in my discussion of the motifs, for they are at present indistinguishable. They are said, however, to have been red and blue patterns on a yellow and white ground (Smith, supra n. 2, I35).

I would like here to express my indebtedness to all those whose assistance made this work possible: Professors Machteld J. Mellink and the late W. S. Smith for their expert advice and guidance through the various stages of the work; Mr. Labib Habashi for his help in my obtaining permission to visit relevant sites in Egypt; and the Ephor of Crete, Dr. S. Alexiou, for enabling me to examine comparative material in the Archaeological Museum in Herakleion. Also I should like to thank Dr. A. H. S. Megaw and Dr. S. Hood for allowing me to look at material from British excavations in Crete, as well as Dr. D. O'Connor for his help with my research in the library of the University Museum. Finally, I am most grateful to Bryn Mawr College for its financial support in the form of an Ella Riegel Fellowship which enabled me to travel to Crete and Egypt.

${ }^{7}$ It is necessary at this point to summarize the chronological framework within which such comparisons can be made. Painted XIIth Dynasty tombs range in date from the reign of Amenemhat I (1991-I962 B.c.) to that of Amenemhat III (I $842-1797$ B.c.). Hepzefa was originally nomarch of Assiut, but was later moved to Kerma in the Sudan to be in charge of an important Egyptian trading post there. His tomb was completed in the reign of Sesostris I (1971-r928). Apparently to the reign of Sesostris I also belongs the first known developed $\mathrm{S}$-spiral design, from a sealing with the name of the pharaoh on it found at Lisht (Kantor, 23). In the following reign, that of Amenemhat II, the Tod treasure shows that at least by the 
tomb known of the Middle Kingdom (it is ca. 44 $\mathrm{m}$. long and consists of seven rooms). Its Great Hall, which lies at right angles to an arched entrance way, has a painted ceiling with a line of a hieroglyphic inscription running down the axis of its greater length. On each side of this inscription the surface is divided into rectangular panels of different sizes covered with various types of designs which are generally repeated on two or more panels. Some of these designs copy traditional models, such as variously painted checkers, each containing a quatrefoil, ${ }^{8}$ or the matting pattern (pl. 5, figs. I c, 2 c) but the majority ultimately derive from spiraliform prototypes. They create a rich decorative effect which more than matches the grandeur of the architecture.

One of the most unusual spiraliform patterns which appear on the tomb's ceiling is illustrated in pl. 5, figs. I b, 2 a; 3 b, 4 a. Like most surface designs, this consists of a network of continuous or interlinked linear elements with small independent motifs filling the background spaces. The basic unit, which by repetition forms the overall design, can be identified as a pair of tangent spirals; the coils start from central loops, unwind two up and two down, and converge to form heart-shaped outlines. At the same time the coils link with those of the adjacent double spirals to form a decorative band consisting of a double row of heart-shaped motifs alternately pointing up and down (pl. 6, fig. 5). Each scrolled heart-shaped unit is marked along its interior line with regularly spaced notches, three on either side of the outline. A simple fourleaved palmette emerges from the joint of the two spirals and rises towards the point of the heart. The juxtaposition of similar borders extends the decoration over the rest of the panel. In this arrangement the hearts are so placed that the points

MM IIA period the Egyptians had been exposed to Minoan art, even though the artifacts in it reached Egypt indirectly in this case. The importation of MM IIA and B Kamares pottery is well attested by finds made at Harageh and Kahun, the former datable as late as the reign of Sesostris II, the latter as late as the Second Intermediate (see $\mathrm{H}$. Kantor in Chronologies in Old World Archaeology, ed. R. Ehrich [Chicago 1965] 2122). The tomb of Hepzefa then dates to a period in which more tangible evidence for contact, whether direct or indirect, is lacking.

8 The painted checkers containing quatrefoils are a typical ceiling pattern used during the Middle Kingdom, Newberry (supra n. 3) pl. vi.

9 Both figure-8 and S-spirals occur, the former on Middle Kingdom and on later scarabs, the latter both on Egyptian Middle Kingdom and on Minoan seals. For examples of figure8 spirals see W. M. F. Petrie, Buttons and Design Scarabs rather than the scrolls touch each other between successive bands. As a result, every two contrasting hearts create the impression of a figure-eight motif with open ends forming scrolls, to be discussed infra.

It is important, however, that our pattern should not be confused either with the figure-eight or with S-spirals both of which exist independently in art. ${ }^{9}$ It is clear from Pl. 5, figs. I b, 2 a; figs. 3 b, 4 a, that the lines of opposite hearts are not rendered by continuous brush strokes, as erroneously suggested by modern schematic reproductions of the motif, ${ }^{10}$ and that even the pointed ends do not quite touch in some cases. It appears, therefore, that the artist had a heart- or leaf-shaped motif in mind. Any resemblance to the figure-eight spirals, which we encounter on scarabs, is probably accidental. On the other hand we have to explain differently the painted border over a doorway in the Middle Kingdom tomb of Ukhhotp at Meir, ${ }^{11}$ consisting of figure-eight spirals similar to those carved on scarabs. ${ }^{12}$ This tomb is later than that of Hepzefa and the artist may have simplified the original or confused it with the figure-eight patterns on scarabs. Egyptian artists usually copied extensively both from their contemporaries and their predecessors, often with increasing divergence from the prototype. The discrepancies between painted representations of Keftiu in successive tombs of the XVIIIth Dynasty have been plausibly interpreted as an instance of uninformed copying. ${ }^{13}$

To summarize: the heart-shaped motif just described is quite uncommon in Egyptian art. It does not appear till the Middle Kingdom, more specifically within the reign of Sesostris I in the tomb of Hepzefa, and then, aside from ceiling decoration, only rarely on an occasional scarab (pl. 6, fig. 7). It appears again later in wall-painting ${ }^{14}$ and on

(London 1925) pl. viI, 93, 264; for S-spirals, ibid., pl. vir, 24, $7 \mathrm{I}$, and on a piece of jewelry in W. M. F. Petrie, Abydos III (London I 892) pl. xII, I. In Crete the S-spiral appears as early as the EM period on a well-dated seal from Mochlos (J. Pendlebury, The Archaeology of Crete [London 1939] 72, fig. Io b).

${ }^{10} \mathrm{Sir}$ J. A. Wilkinson, Manners and Customs of the Ancient Egyptians I (London I 878) pl. viII, 7.

11 Blackman (supra n. 2). Compare with this the pattern on the ceiling of the tomb of Wahka II at Qaw (Petrie, supra n. 2) of the date of Amenemhat III.

12 Petrie (supra n. 9).

13 Kantor, 42.

14 One such example is the decoration of heart-shaped motifs on the sails of a boat painted in a tomb which is tentatively dated to the reign of Thutmose III (Nina de Garis Davies, $A n$ cient Egyptian Paintings II [Chicago 1936] pl. xxviII). 
ceilings. ${ }^{15}$ It is not unlikely that in the Middle Kingdom this may have been a painter's experiment with a new decorative form, which was not applied in other artistic media and never quite gained the popularity of other motifs with a longer Egyptian tradition. It is perhaps in the arrangement and detail of the design that we can trace typical Egyptian artistic tendencies. Thus, the combination of a purely geometric motif, here a spiral, with naturalistic elements, here the interior palmette and perhaps the notches which could suggest the thorns of the stalks of a plant, is a common Egyptian practice in surface design. ${ }^{16}$ The palmette itself derives from earlier Egyptian art. Palmettes appear on faience tiles of Middle Kingdom date belonging to the decoration of the façade of a chapel at Kerma in the Sudan. ${ }^{17}$ The placement of the palmette within a pointed arch, moreover, brings to mind the Egyptian hieroglyph for tree (pl. 6, fig. 14) or the less stylized arrangement of two curved converging leaves enclosing a bud-a favorite motif in Old Kingdom decorative art. ${ }^{18}$

Keeping in mind the basic features of the Egyptian spiral motif, I should like to draw a comparison between it and the Minoan ivy-leaf and other related patterns to which I believe the heart-shaped unit bears certain affinities. The basic obvious similarity is that of the outline: in Egyptian examples it is here conventionally called "heart-shaped" and in Minoan archaeology has been compared to an ivy leaf. Evans derives the ivy leaf from the C-spiral which appears as early as the EM period in Crete, ${ }^{19}$ but Furumark rightly objects that this attribution does not explain the pointed termination of the leaf and prefers to assign it to a ceramic motif common in Kamares pottery. ${ }^{20}$ Simple forms of this pattern actually appear as early as the EM III period, though more commonly from MM I on. ${ }^{21}$ Its usual arrangement is that of a single frieze in

\footnotetext{
15 Smith (supra n. 2) 135.

${ }^{16}$ Smith (supra n. 2) 132.

${ }^{17}$ Smith (supra n. 2) 40; fig. 6o. Smith attributes the development of these palmettes to Old Kingdom voluted forms.

${ }^{18}$ Smith (supra n. 6) 5I, fig. 21; 52, fig. 22.

19 Evans, Palace of Minos (London 1921-37; hereafter PM) II 480 .

${ }^{20}$ A. Furumark, The Mycenaean Pottery: Analysis and Classification (Stockholm 194I) 140. See also Matz (supra n. 4) for similar comparisons.

21 The following are some of the ceramic examples, mentioned chronologically: sherd from Gournia of the EM III period ( $P M \mathrm{I}_{1} \mathrm{II}_{3}$, fig. 8o a, 6); sherd from Palaikastro and cup from Phaestos of the MM I period (BSA, Suppl. I [1923] pl.
}

which the leaves point in the same direction and are often linked. The closest parallel to the Egyptian scheme is provided by a recently found, as yet unpublished, pot from Kea dated to the LM IB period (pl. 6, fig. 6) ${ }^{22}$ Here the decoration, which covers most of the body of the pot, consists of interwoven friezes in each of which heart-shaped motifs point alternately up and down (compare with pl. 6, fig. 5). In the Minoan ceramic examples an interior filling motif sometimes occupies the angle, but more usually it links the tangent spirals. This motif is sometimes geometric, such as a C-curve or two lines forming an acute angle, and sometimes, especially from the MM II period on, derived from plant or flower motifs (pl. 6, figs. ro, 9).

The heart-shaped pattern also occurs frequently on Minoan seals, usually as an isolated pattern (pl. 6, fig. 8) and more rarely in conjunction with other motifs. ${ }^{23}$ More common as an engraved pattern, however, is the related C-spiral which fits more appropriately the rounded space within a seal. The interior filling motifs in the latter case are similar to those of the leaf-shaped spiral. ${ }^{24}$

In Minoan wall-painting early examples of our motif are scanty and indistinct. Heart-shaped outlines are faintly drawn on the neck and wings of a miniature griffon and on a sphinx, on two small fresco fragments from Knossos, ${ }^{25}$ thus anticipating the use of such curves on later representations of such fictitious animals. In these miniatures there is no filling ornament and the entire design is in any case so simple that they may even be unrelated to the ceramic motif which is already well defined at a much earlier date. The case is different in the naturalistic paintings of the transitional MM IIIB to LM IA period. There the motif loses its geometric character and is incorporated into an imaginary plant. The Blue Monkey Fresco from the House of Frescoes at Knossos well illustrates such a transformation. Here the ivies are the leaves of a

xI, A; L. Pernier, Il Palazzo Minoico di Festòs I [Rome 1935] pl. xxI); MM IIA sherd from Phylakopi ( $P M$ I, 246, fig. I 86 d); LM I sherd from the Royal Villa at Knossos ( $B S A 9$ [19023] 153 , fig. $92 \mathrm{i}$ ).

22 The photograph of a watercolor reproduction of the above pot has been kindly given to me by Professor J. L. Caskey. The vessel is dated stylistically to the LM IB period or earlier by Dr. E. Milburn, in her doctoral dissertation for the University of Cincinnati (p. I 8).

23 V. E. G. Kenna, Cretan Seals (Oxford 1960) 43, fig. 68; $P M$ I, 700 , figs. 523 a, b.

24 Compare the two motifs on seals from Phaestos: Annuario 19-20 (1957-58) 134, fig. 341; 95, fig. 218.

${ }^{25} P M$ III, 4 I, fig. 25 f, d. 
spreading plant and their interiors are further provided with papyrus tufts (pl. 6, fig. I2). In the Procession Fresco from the Palace of Knossos the leaf-shaped motif retains its naturalistic features (such as the dots which suggest anthers), but is used as a textile pattern on the costume of one of the figures. ${ }^{26}$ The closest parallel, even to the detail of the palmette, is the crest of the iris flower in the King Priest stucco relief, also from Knossos. ${ }^{27}$ Here, however, we are in a period for which artistic exchange between Egypt and the Aegean is more amply attested. ${ }^{28}$

It is clear from these examples that, in spite of the versatility of the spiral motif, Egyptian and Minoan versions have a common denominator. On the other hand, since this type of spiral design first appears in Crete, it is most probably borrowed by Egypt and, as has been assumed for related patterns, it was probably transmitted by exported Minoan embroidered or woven patterned textiles. ${ }^{29}$ As the motif first appears in the tomb of Hepzefa, within the reign of Sesostris I (I97I-I928), a date a little prior to the MM I period seems the most likely one for its adoption in Egypt. On the other hand, the progressive naturalization of the motif in Minoan art from the MM II period on, together with comparable phenomena in Minoan ceramic decoration, to be discussed next, may reflect a counter-effect of Egyptian on Minoan style.

Combinations of geometric with naturalistic elements occur in Minoan pottery mostly in the MM II period and later. Earlier the two types of design are often used concurrently, but are not fully integrated. In the MM II period spirals and plant motifs blend in a manner reminiscent of the spiral decoration in the tomb of Hepzefa. ${ }^{30}$ Among these examples the most interesting in connection with the notched outline of the Egyptian motif is the

\footnotetext{
${ }^{26} P M$ II, 729, fig. 456 c.

$27 P M$ II, 787 , fig. 513.

28 This is the period to which Evans attributes what he describes as an "Egypto-Minoan" decorative style (PM II, 733). Miss Kantor defines the interaction more accurately as one between Egypt and the Aegean, rather than exclusively Crete, Kantor 33 ff.

29 Kantor 29.

${ }^{30}$ Excellent examples of such a combination are those on a polychrome pithos from Phaestos of the MM II period (S. Marinatos, Crete and Mycenae [New York 1960] pl. x) and on a painted basin from Knossos of the MM III period ( $P M$ I, 598, fig. 439).

${ }^{31} \mathrm{~J}$. Hazzidakis, Tylissos à l'époque Minoenne (Paris I921) pl. Ix.

32 Comparable, with the omission of the spiral base, are also
}

design on a MM II fruitstand from Phaestos, consisting of spirals marked by continuous solid triangles (pl. 6, fig. 13). Similar triangles mark the concentric curves of the so-called fan in one of the frescoes from Tylissos. ${ }^{31}$ It is harder to find Minoan parallels for the palmette. A simple plant grows out of a base of double spirals and is placed within an arched outline, both in a sign of Minoan hieroglyphic script and as a seal design (pl. 6, figs. 15I6). ${ }^{32}$ The best comparison, however, is with a faïence pendant from the Temple Repositories at Knossos (pl. 6, fig. II). Here the design consists of a lily gracefully enclosed within the heart-shaped space between two converging leaves. Two more leaves flank the core of the plant with little palmettes filling the interstices. The entire latter design should probably be connected with a circular composition with a lotus bud and flower and papyrus elements, which appear in Old Kingdom art. ${ }^{33}$

With more general comparisons in mind, we should finally pay some attention to the decoration formed between the network of the heart outlines on the Egyptian ceiling. Lozenge-shaped spaces with incurved sides are formed between successive bands of spirals and thus each horizontal line of hearts alternates with one of lozenges. A solid lozenge containing three small crosses $^{34}$ fills each space which has an interior outline of light dots. Such background spaces are common in Egyptian overall designs, which often consist of contrasting zigzag lines. ${ }^{35}$ It is interesting, by way of comparison, that in frieze arrangements on Minoan pottery lines of small discs or dots may run parallel to the outlines of each frieze and produce an effect analogous to that of the spiral decoration in Hepzefa's tomb (pl. 6, fig. I7). ${ }^{36}$ Though dots are frequently used on earlier Minoan pottery and are typical in painted representations of textiles in

the plant motifs on a MM IA sealing and on a MM IIA fragment of a bowl, both from Knossos (PM I, 202, fig. I5I; $P M$ IV, II9, fig. 86, respectively).

33 Smith (supra n. 6) 5I, fig. 2I c. This connection was pointed out to me by Professor Smith in a letter.

34 This motif of three crosses, of which the central one is larger, is no longer visible, but is recorded in Baroness von Bissing's reproduction (Smith supra n. 2).

35 See Emery and Quibell (supra n. 3).

36 Besides the Kamares jar found at Abydos and partially illustrated in one of my drawings (pl. 6, fig. 17), we should mention as additional examples the decoration on a MM II cup from Palaikastro (PM IV, I33, fig. IOI), the design on a votive girdle from the Temple Repositories ( $P M$ I, 506, fig. 364 c), and a pattern on the dress of a woman in a stucco relief from Pseira ( $P M$ II, 732, fig. 458 ). 
Crete, ${ }^{37}$ the specific use of dots in friezes first appears in the MM II period. If we do not dismiss this similarity as an accidental one, it is wise to keep in mind that such a scheme might have been used on Minoan textiles earlier than on the pottery or in the painted representations which have survived. A similar transfer of the scheme cannot be supported on the Egyptian side, for it has been convincingly demonstrated by Miss E. Riefstahl that the ancient Egyptians did not use any patterns on their textiles except some extremely simple ones. $^{38}$

The next motif to be considered further illustrates the rich imagination of the artist of Hepzefa's tomb. We can designate it as the "angle" motif -reproduced in pl. 5, fig. I a, and in a schematic drawing in pl. 6, fig. 20. Like the previous pattern it has been frequently considered in comparative studies of ancient ornament. ${ }^{39}$ Though there can be several possible ways of viewing or describing an intricate overall design, the following method is aimed at emphasizing a specific point: that this pattern is basically a rectilinear variant to the heartshaped spiral or derives from a closely related prototype.

In Baroness von Bissing's reproduction of the decoration of the ceiling, as well as in my drawings, the patterns can be broken up more clearly into constituent units than in those shown in older publications. ${ }^{40}$ The new drawings make clear the correspondence between the basic elements of this motif and of the spiral previously described. The angle, which forms the basic unit of the design, corresponds to the heart-shaped outline and its bent ends to the scrolled ends (pl. 6, figs. I8-ig). The function of the palmette is taken over by two joining lines within the angle. The resemblance is not quite obvious at first, partly because the previ-

\footnotetext{
${ }^{37}$ The following are references to some of the fragmentary designs which have been interpreted as parts of representations of costumes in Minoan wall-paintings: $P M$ III, 38, fig. 21; $P M$ II, 75I, fig. 485; PM III, 330, fig. 220.

38 E. Riefstahl, Patterned Textiles in Pharaonic Egypt (New York 1944) I 8.

39 Kantor, 29, describes it as a "rectilinear version of two axially symmetrical S-spirals." Matz (supra n. 4), I $78 \mathrm{ff}$, sees in it a system of S-spirals arranged obliquely to rows of angular C-maeanders.

40 Compare Wilkinson's reproduction in Matz (supra n. 4) I 78, fig. 71, to that in Smith (supra n. 2) fig. I67.

${ }^{41} \mathrm{~A}$ variant of the above design occupies another panel. It is identical to the one just described with the omission of a filling motif in this case (Smith [supra n. 2] fig. 167-the top left panel in the illustration). Unfortunately $I$ was unable to record this in a photograph.
}

ous motif had not been properly defined, partly because the basic units are disposed differently in the two panels (pl. 5, figs. I a, b). In the first panel all the angles point in the same direction. The undefined triangular spaces formed between the rows that the angles form automatically point in the opposite direction, thus creating a two-way movement. In addition to the system of angles, an independent network of continuous lines breaks up the background. These are set parallel to the angles and, as they turn around the bent ends of the latter, they create a maeander-like effect (pl. 6, fig. $20)$. Both the interior of the angles and the background spaces are filled by solid lozenges containing a quatrefoil, two petals of which meet at right angles with two pairs of smaller petals. Here again we have a combination of purely ornamental with naturalistic elements. ${ }^{41}$ Other versions of the same motif occur in the tomb of Wahka II at Qaw, of the later XIIth Dynasty, and in that of Pedamenotep at Thebes of the XXVIth Dynasty. ${ }^{42}$

If we assume a connection between the angle and the heart-shaped motifs, it is clear that the comparisons with Minoan art made supra can still hold true in this case. Perhaps we can claim that here the arrangement of the angles is closer to that of ivies in Minoan ceramic examples, where they generally point to the same direction. The resemblance becomes more striking in the case of a MM I cup from Palaikastro on which a solid lozenge occupies the angle of the heart (pl. 6, fig. Io).$^{43}$ On the other hand, we can view the Egyptian design differently -these patterns were probably intended to be looked at in various ways-and decide that the background spaces are of equal visual value. In such a case, the movement of the angles seem to alternate up and down. ${ }^{44}$

\footnotetext{
42 Kantor pl. vi D, F.

43 Related perhaps to the same design is an unpublished painted frieze of angles underlining spirals in stucco relief which decorated the top of the walls of the so-called Banquet Hall in the west wing of the recently excavated palace of Kato Zakro. Here the two lines, which normally form a lozenge within the angle, do not meet each other.

${ }^{44}$ Matz rightly draws a comparison between the angles which change direction in each row (if we take the intermediary spaces into account) and the design on a golden breastplate from Shaft Grave V at Mycenae (Matz 179; 153, fig. 50). To this comparison we can add a second example, in this case from Kerma. It is a large clay vessel with an incised decoration consisting of interlinked rows of $\mathrm{S}$-spirals. The technique, which is encountered on pottery found in Egypt, has been described as Syro-Palestinian. Though the pottery at Kerma ranges from the XIIth Dynasty, when Hepzefa was there in control,
} 
Finally, we turn to a panel illustrated in pl. 5, figs. $2 \mathrm{~b}, 4 \mathrm{~b}$. The design is very close to one copied by Baroness von Bissing, ${ }^{45}$ but less canonical in its organization and less precise in execution. The pattern is clearly guided by a grid, the lines of which run diagonally to the sides of the panel. The inner divisions thus form lozenges. A number of consecutive rows of lozenges have maeander motifs, and these rows alternate with a single row filled with rosettes and solid lozenges surrounded by white discs, like those in the panel with the heart-shaped motif.

The maeanders are drawn inconsistently which, in addition to the worn state of the ceiling, makes it hard to analyze them. In the most carefully rendered parts, it seems that the maeanders consist of two pairs of rectilinear C-spirals placed back to back (pl. 6, fig. 2I). If this definition is correct, the design could be compared with the systems of antithetic circular and squared C-spirals incised on Cycladic pottery and later painted in the Labyrinth Fresco from Knossos. ${ }^{46}$ The other two motifs are more carefully reproduced. The rosette has eight petals, six light and two dark in color, and is placed within a light-colored disc within each individual lozenge. Rosettes appear as early as the MM I period on seals, ${ }^{47}$ but the particular type consisting of eight petals set within a disc occurs first in MM II pottery.$^{48}$ Our conclusion in regard to the decoration of the present panel, however, must remain tentative until a better version comes to light.

In summary then, the heart-shaped motif seems to have been transmitted to Egypt early in or a little prior to the MM I period, probably together

to the Second Intermediate, most of these Syro-Palestinian pots date to the latter period (Smith [supra n. 6] II 8, pl. 8I B).

${ }^{45}$ Smith (supra $n .2$ ) fig. 167 , left panel at the bottom.

${ }^{46}$ Kantor pl. IV B, D, C. with its friezelike arrangement and a dotted background, and probably by means of exported Minoan textiles. The specific use of the basic motif and its translation into a potentially endless surface pattern, as well as its squared version in other panels, should be attributed to the Egyptian adaptation. Hepzefa's artist certainly showed great inventiveness in rearranging and elaborating upon a simple motif to create brilliant new decorative schemes in which the constituent parts are often hardly discernible. It is also to his credit that, while variety was achieved, a certain uniformity and harmony was maintained throughout the entire ceiling decoration.

The MM II period may be viewed in some respects as one of a reversal of influence. Thus the Egyptian combination of decorative with naturalistic forms, so well exemplified in the tomb of Hepzefa, may not be entirely unconnected with the flourishing of the naturalistic ceramic style of the MM II and MM III periods in which the spiral and other geometric motifs still play a major role. It has been suggested elsewhere that Middle Kingdom representational art may have spurred the subsequent rise of wall-painting in Crete. ${ }^{49}$ While it is feasible to assume a perishable medium for the transmission of Minoan motifs, without definitive archaeological evidence we cannot explain how the Minoan artist became familiar with major Egyptian art, as he must have been if we accept the affinities between the two arts, shown supra and in other studies, as more than accidental.

\footnotetext{
ATHENS

${ }^{47}$ Matz (supra n. 4) pl. vi ki67, k27.

48 N. Platon, Crete (Geneva 1966) pl. 88.

${ }^{40}$ Smith (supra n. 2) 132, I 33.
} 

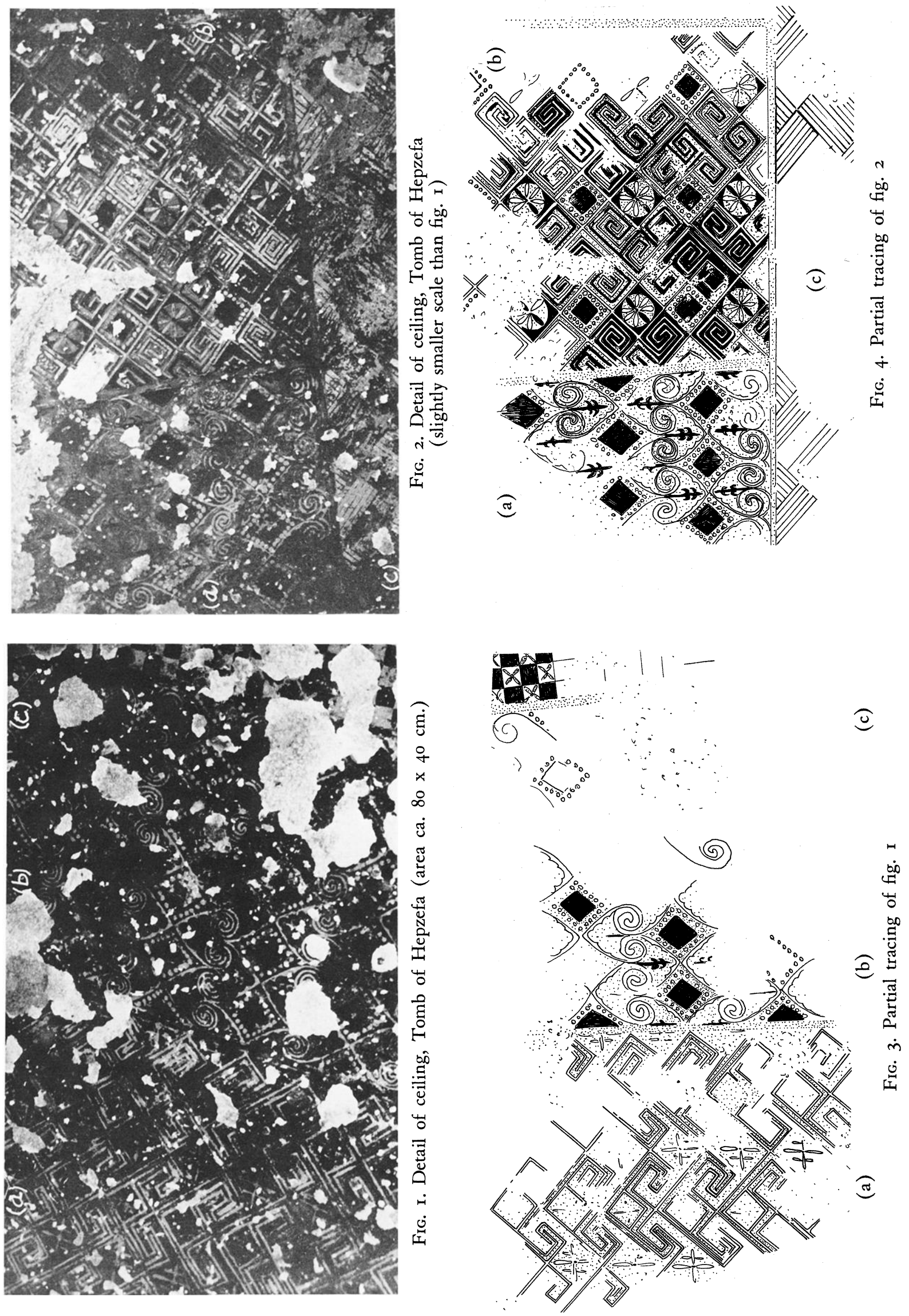

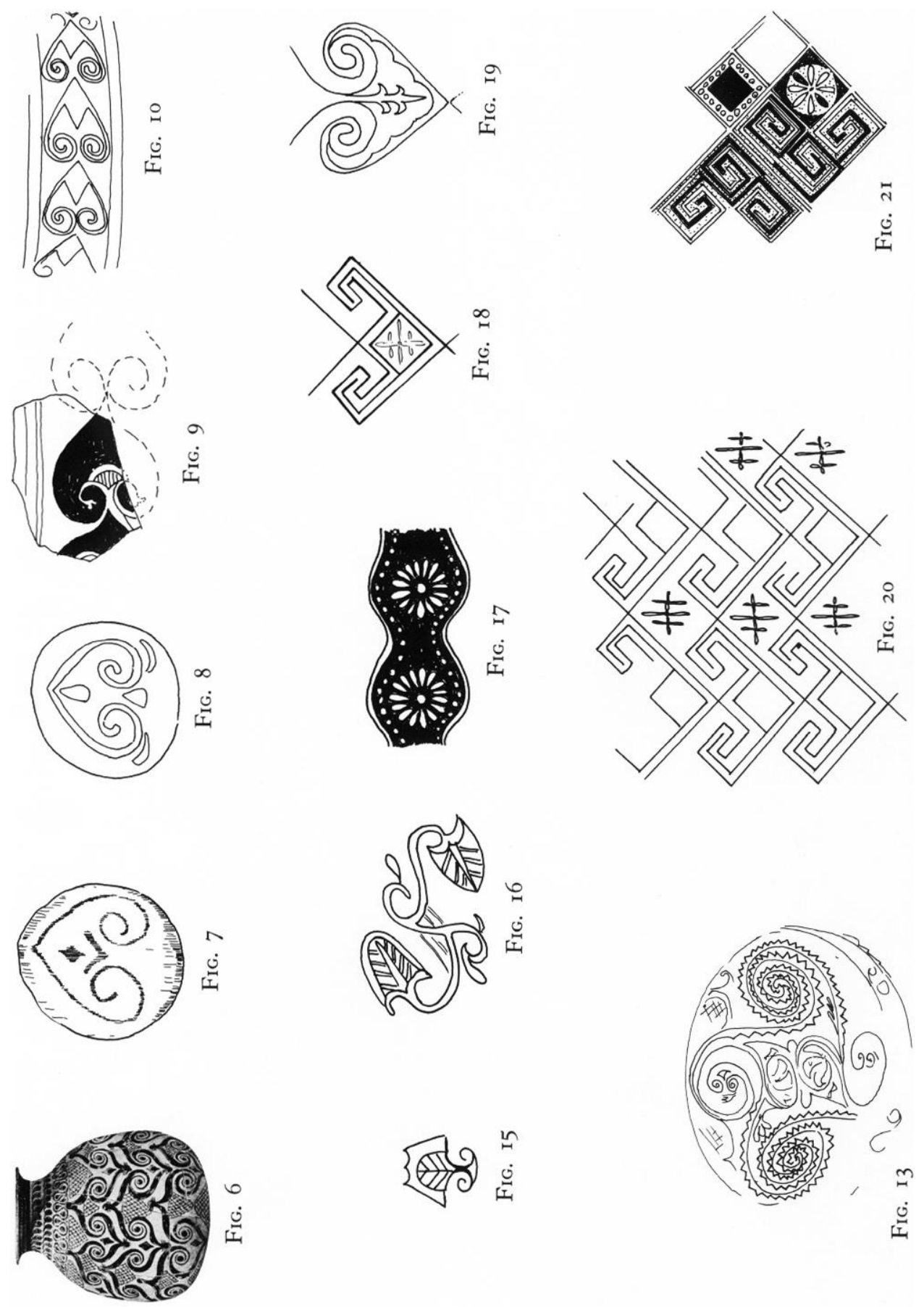

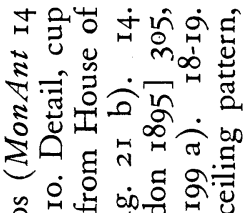

ㄱ. 웁해윰

i द.

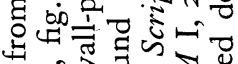

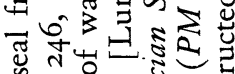

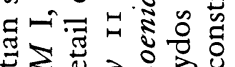

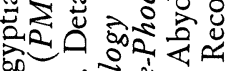

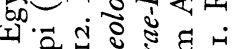

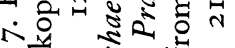

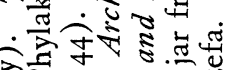

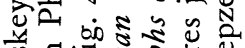

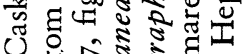
ن.

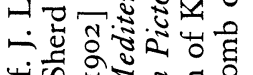
पूंक

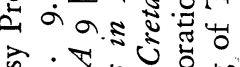

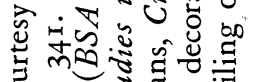

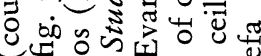

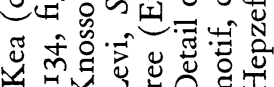
的口四 द्वि

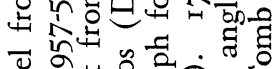

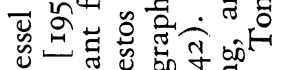

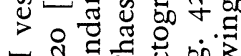

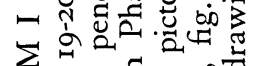

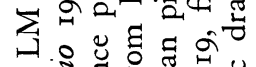

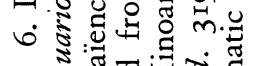

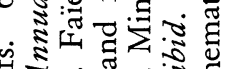

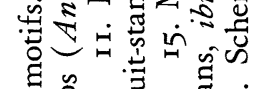

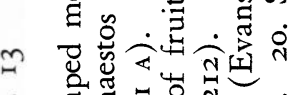

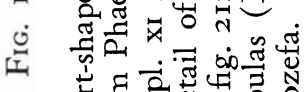

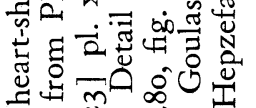

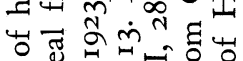

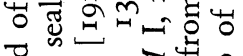

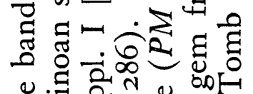

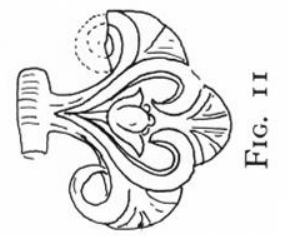
․ㅜㄹ

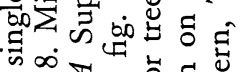

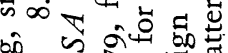

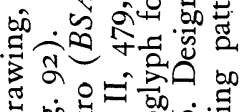

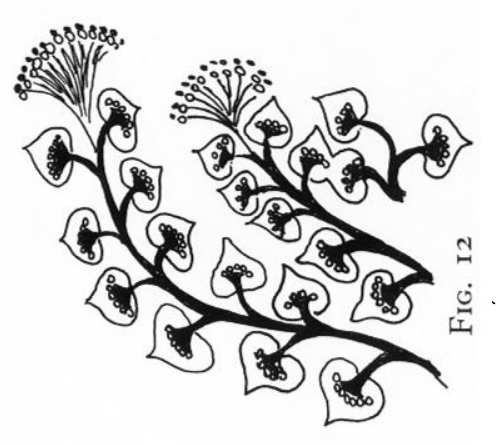
पै

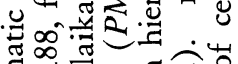

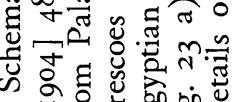

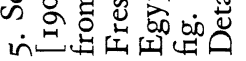

